\title{
JUDICIALIZAÇÃO DA POLÍTICA DE SAÚDE E FEDERALISMO NO STF: O CASO DAS ADI 2999 E 3088
}

\section{JUDICIALIZATION OF HEALTH POLICY AND FEDERALISM IN THE BRAZILIAN SUPREME COURT (STF): THE CASE OF ADI 2999 AND 3088}

\author{
FELIPE RANGEL DE SOUZA MACHADO ${ }^{1}$ \\ DORIVAL FAGUNDES COTRIM JUNIOR ${ }^{2}$
}

\begin{abstract}
RESUMO: $\mathrm{O}$ artigo analisa o processo jurídico e político mobilizado em busca do poder discricionário sobre os gastos do orçamento do Fundo Estadual de Saúde. Trata-se de uma disputa travada no STF expressa na ADI 2999 (Estado do Rio de Janeiro X Conselho Nacional de Saúde) e na ADI 3088 (PSDB X Estado do Rio de Janeiro). A análise das ADI foi feita com base em um enfoque qualitativo, por meio da análise da retórica. Além disso, seguimos quatro passos metodológicos de análise de processos judiciais: 1) a análise dos antecedentes do processo; 2) a análise da sustentação jurídica; 3) o acompanhamento da construção da decisão; e, 4) a avaliação da efetividade da decisão. O estudo evidenciou que a principal questão presente nas ADI foi um conflito federativo no qual o Estado do Rio de Janeiro buscou assumir a proeminência sobre a decisão dos gastos em saúde. Conclui-se que a atuação do STF permite abordar o fenômeno da judicialização não apenas mediante os efeitos das decisões presentes nas sentenças, mas também pela disputa de argumentos presentes nas ações e pela mobilização do Legislativo e do Executivo.
\end{abstract}

PALAVRAs-ChAVE: Judicialização; Federalismo; Saúde; STF.

\footnotetext{
${ }^{1}$ Pesquisador Titular em Saúde Pública na Escola Nacional de Saúde Pública Sérgio Arouca, da Fundação Oswaldo Cruz (ENSP/Fiocruz), Rio de Janeiro, RJ, Brasil. Possui Doutorado e Mestrado em Saúde Coletiva pelo Instituto de Medicina Social da UERJ (IMS/UERJ). Possui graduação em Ciências Sociais. Tem desenvolvido reflexões acerca da construção de direitos na área da saúde e suas repercussões sobre os processos de determinação social na saúde, o que implicou estudar o papel dos conselhos de saúde, do Ministério Público e do Poder Judiciário. Tais reflexões ocorrem no âmbito das Políticas Públicas de Saúde e das formas de atuação do Estado Brasileiro e sua relação com a sociedade civil. Integra o grupo de pesquisa Núcleo de Estudos em Democratização e Sociabilidades na Saúde (NEDSS), é membro da Associação Brasileira de Saúde Coletiva (ABRASCO).

${ }^{2}$ Doutorando em Saúde Coletiva do Instituto de Medicina Social da UERJ (IMS/UERJ) e em Direito da Pontifícia Universidade Católica do Rio de Janeiro (PUC Rio). Mestre em Teoria do Estado e Direito Constitucional pela PUC Rio. Especialista em Direitos Humanos e Saúde pela Fundação Oswaldo Cruz (FIOCRUZ). Graduado em Ciências Jurídicas e Sociais pela Faculdade Nacional de Direito (FND/UFRJ). Professor do Instituto de Direito da PUC Rio.
} 
ABSTRACT: In The article analyzes the legal and political process mobilized in search of discretionary power over State Health Fund budget expenditures. This is a dispute that was take place in the STF expressed at ADI 2999 (State of Rio de Janeiro X National Health Council) and at ADI 3088 (PSDB X State of Rio de Janeiro). The analysis of these ADI was based on a qualitative approach through rhetorical analysis. In addition, we follow four methodological steps of judicial process analysis: 1) the analysis of the process history; 2) the analysis of legal support; 3) the process monitoring the construction of the decision; and 4) the evaluation of the effectiveness of the decision. The study showed that the main issue at ADI was a federative conflict in which the state of Rio de Janeiro sought to take prominence over the decision on health spending. It is concluded that the action of the Supreme Court allows to consider the phenomenon of judicialization not only through the effects of decisions present in judgments, but also by disputing arguments present in actions in courts and by mobilizing the Legislative and Executive.

KEYWORDS: Judicialization; Federalism; Health, STF.

\section{INTRODUÇÃO}

A Lei Complementar n. 141 (LC 141) de 2012, buscou, entre outras coisas, regulamentar o uso dos recursos da saúde com base na Emenda Constitucional n. 29 (EC 29) estabelecendo "as normas de fiscalização, avaliação e controle das despesas com saúde nas 3 (três) esferas de governo". Conforme argumentou o Senador proponente do Projeto de Lei (Tião Viana), "a definição dos conceitos de ações e serviços públicos de saúde é feita de modo a impedir que atividades alheias à área sejam financiadas com recursos da saúde e que a população fique desassistida ${ }^{3 \prime}$. Movimento semelhante já havia sido feito pelo Conselho Nacional de Saúde (CNS) em 2003 quando editou a Resolução n. 322 que definia a base de cálculo para a apuração dos recursos mínimos a serem aplicados na saúde. No entanto, tal resolução provocou uma intensa disputa jurídico-normativa que ganhou corpo no STF e só foi resolvida, de fato, com a promulgação da LC 141. O pano de fundo dessa disputa se deu em torno da questão federativa brasileira que tomou assento nos bancos do Supremo Tribunal do Brasil. Entendemos que esse contexto evidenciou um importante caso de Judicialização da Política que merece ser compreendido. Embora o termo 'judicialização' venha sendo banalizado nos últimos anos - ou não sirva mais como referência que possa "agregar o conjunto da produção científica sobre comportamento de instituições judiciais no Brasil" (SILVA, 2018, p.35) - insistimos em sua utilização pois, no caso estudado, algumas das condições apresentadas por Tate (1995) são bastante evidentes, especialmente a existência de grupos de pressão que tenham identificado nos tribunais judiciais

${ }^{3}$ Disponível em: https://bit.ly/35yliog 
possíveis arenas para a veiculação de seus interesses, buscando angariar resultados políticos pelas vias judiciais.

Neste artigo discutiremos a utilização da Ação Direta de Inconstitucionalidade (ADI) como forma de atuação política por meio do Judiciário. Alguns autores (VIANNA et al, 1999) têm defendido que a crescente proposição de ADI tem feito com que o Supremo Tribunal Federal (STF) deixe de atuar como coadjuvante na produção de leis, assumindo cada vez mais lugar de destaque.

Para Pogrebinschi (2011) não é o número de ADI que qualifica o fenômeno da judicialização no país, mas o resultado efetivamente emanado das ações decididas pelo STF. Esta autora sustenta que o STF ao invés de estar assumindo uma postura ativa no cenário político nacional, tem impulsionado o Congresso Nacional a assumir sua função de legislador. No caso das políticas de saúde, defendemos a existência de uma posição híbrida que compreende o STF como o lócus onde desembocam divergências políticas e que os procedimentos próprios do julgamento (suas fases, partes, pareceres etc.) dão o tom da profundidade do fenômeno da judicialização no Brasil.

Mais que isso, na medida em que se leva ao Judiciário questões políticas está se buscando balizá-las na forma do direito, retirando, portanto, parte de seu significado histórico que inclui lutas e acordos políticos (BOURDIEU, 2006). Assim, reforçamos que a ênfase na expressão jurídica de assuntos políticos constitui-se também como marca do fenômeno da judicialização. Assim, "já seria possível observar uma política "judicializada" se os atores políticos levassem em consideração [no momento mesmo da produção da política] as preferências do tribunal em suas interações, antecipando-se estrategicamente a possíveis decisões judiciais futuras, de modo a evitar que ocorram de fato" (RIBEIRO e ARGUELHES, 2019, p.9).

Dentre os possíveis propositores de ADI se destacam os Governadores de Estado e os Partidos Políticos com representação no Congresso Nacional. A utilização da ADI como instrumento de disputa política por esses grupos de propositores é uma especificidade da Judicialização pouco aprofundada nos estudos sobre o tema. Vianna et al (1999) analisaram as ADI ajuizadas entre $1988 \mathrm{e}$ 1998 concluindo que, dependendo da origem do grupo ou instituição que aciona o STF, este recebe um chamado diferente. Os governadores demandam ações visando racionalizar a administração pública; a Procuradoria chama o STF a uma gestão entre os diversos aparelhos ligados à prestação da justiça (polícia, cartório, MP); as confederações querem que o STF funcione como um substitutivo às ações do Welfare State (ESPING-ANDERSON, 1991); e os partidos políticos buscam uma atuação mais clássica na judicialização da política, tal qual as ações dos governadores voltadas para questões da Federação.

Neste sentido, é possível observar que é no Judiciário que desembocam as questões relativas à definição e redefinição de competências de cada ente federado. O tema das relações federativas ganhou espaço nas discussões do STF, parecendo 
ser esta a principal característica da Judicialização requerida a partir do instrumento específico da ADI no caso da saúde. Reforça esse quadro o fato de o modelo federativo do Brasil ter na União seu principal poder unificador (ARRETCHE, 2012). Isto significa que os anseios dos entes inferiores poderão encontrar limites superiores, caso tentem exceder o que lhes é permitido.

Na área da saúde, a estrutura jurídica brasileira apresenta alguns desafios que ainda não foram solucionados. O principal deles, no que diz respeito aos objetivos deste texto, é o formato concorrente da maior parte das políticas sociais brasileiras, na medida em que, na Assembleia Nacional Constituinte, todas as propostas que combinavam a descentralização das atribuições com a descentralização dos recursos foram derrotadas.

Assim, qualquer ente federativo estava constitucionalmente
autorizado a implementar programas nas áreas de saúde,
educação, assistência social, habitação e saneamento.
Simetricamente, nenhum ente federativo estava
constitucionalmente obrigado a implementar programas nestas
áreas (ARRETCHE, 2004, p.22).

Estudos têm demonstrado que apesar dos avanços presentes na Constituição Federal de 1988 (CF 88), seu texto apresenta diversas contradições e omissões que evidenciariam traços conservadores do momento histórico anterior (BAPTISTA, MACHADO e LIMA, 2009; PILATTI, 2020; FAGNANI, 1997).

Para Arretche (2004), esta especificidade inscrita na Constituição gera "superposição de ações; desigualdades territoriais na provisão de serviços". Desse modo, no caso da saúde, o governo federal, a partir da legislação e portarias, tem o poder de formular, coordenar e, sobretudo, financiar as políticas de saúde que serão desenvolvidas em nível local, rompendo com a ideia de aproximação da gestão com a realidade local dos cidadãos, um dos ideais da reforma sanitária (CEBES, 1980). Tais portarias são responsáveis por muitos dos conflitos judiciais, pois, apesar de não terem força de lei, definem a forma e os critérios do repasse de recursos financeiros.

Parte das questões que tangenciam o financiamento das ações de saúde vinculase ao fato de, no Brasil, a tributação ser fortemente centrada na União, o que se justifica pelo federalismo assimétrico ${ }^{4}$ brasileiro. Contudo, é necessário argumentar que a possibilidade de cumprimento das funções sociais definidas na Constituição com base nos princípios federativos implica num alto poder de gasto. Daí a importância dos repasses federais.

\footnotetext{
${ }^{4}$ Federalismo assimétrico significa que existem unidades federativas com composições sociais e culturais que diferem e refletem desigualdades, umas das outras e do país como um todo (RAMOS, 2000).
} 
Compreender este fenômeno específico implica ter clareza sobre a conformação dos arranjos federativos existentes no Brasil, ainda mais complexos no campo da saúde (VIANA e MACHADO, 2009). Para Elazar (1987) a definição mais simples possível do federalismo seria "self-rule plus shared rule" (autogoverno mais governo compartilhado). Sua existência dependeria de uma ótima relação entre o maior grau possível de autonomia dos territórios e uma coexistência harmoniosa e cooperativa dentro da federação. Esta relação deveria ser capaz de gerar consensos. Entretanto, esta definição ideal de federalismo não se efetiva na prática, que se apresenta muito mais como um complexo sistema de competição, para o qual o Judiciário vem sendo chamado, ora como árbitro do processo, ora como legitimador de ações, sobretudo no que diz respeito às ações dos estados.

A inserção do Judiciário nos arranjos federativos ocorre pela dificuldade dos entes federados de pactuarem os termos de suas relações. Além disso, dada a especificidade da elite política brasileira, muitas vezes o que ocorre com os direitos sociais é um permanente "jogo de empurra" entre instituições, em que cada ente tenta se livrar de um conjunto de atribuições. Por isso, para Stepan (1999) os tribunais vêm desempenhando um papel fundamental no sistema federativo. Ribeiro e Arguelhes (2019, p.9) também argumentam que ao compreender o "Judiciário e o STF como atores ou arenas políticas" há uma complexificação na discussão sobre políticas públicas no Brasil.

No sentido de aprofundarmo-nos nessa complexidade, o objetivo deste artigo é analisar o processo jurídico e político mobilizado (Ver Figura 1) por diferentes atores e instituições, tendo como pano de fundo a disputa pela categorização e definição dos elementos financiáveis com o orçamento da saúde. O contexto em destaque foi o ano de 2003 do Governo Rosinha Garotinho no Rio de Janeiro. Neste ano a governadora sancionou pelo menos três leis voltadas para a mesma ação: combate aos sintomas da pobreza. Na primeira, Lei n. 4.086/2003, criou-se uma nova alíquota de impostos; na segunda, Lei n. 4.167/2003, criou-se um programa de trabalho financiado pelo Fundo Estadual de Saúde (FES); e na terceira, Lei n. 4.179/2003, criou-se um programa de alimentação que teria como financiamento parte dos recursos do Fundo Estadual de Saúde (FES).

\section{Procedimentos metodológicos}

Inicialmente realizou-se uma pesquisa com descritores relacionados à saúde na seção de busca por ADI no site do STF. Foram encontrados duzentos e cinquenta e três resultado distribuídos entre os anos de 1988 e 2019. A partir desta busca foi construída uma planilha que sistematizou e classificou todas as ADI. Este material serve de indicativo de como as questões referentes à saúde têm chegado ao STF pela via da ADI.

O estudo desses dados indicou que grande parte das ADI ajuizadas se voltava não apenas para a discussão da saúde e das políticas de saúde, mas para as questões referentes às atribuições de cada ente federado. Isto permitiu selecionar algumas 
ADI para estudo aprofundado. Ressalta-se que no site do STF constam apenas as petições iniciais, o andamento e as decisões. $\mathrm{O}$ acesso físico às ADI, ou seja, ao inteiro teor dos votos e dos pareceres, é possível apenas após a conclusão do processo, quando estas deixam os gabinetes dos Ministros e são encaminhadas para o arquivo do STF.

A literatura (VIANNA et al, 1999; CASTRO, 1997; PACHECO, 2008; TAYLOR, 2007; TAYLOR e DA-ROS, 2008) tem demonstrado que a análise das ADI vem sendo feita exclusivamente sob o enfoque quantitativo. A perspectiva adotada neste trabalho visa aprofundar as questões presentes nas ADI com o tema específico da saúde, o que foi feito a partir de um enfoque qualitativo, por meio da análise da retórica. Foram selecionadas duas ADI (2999 e 3088) que dizem respeito à interpretação do conceito de saúde e a consequente alocação de recursos financeiros nesta área, ambas originadas no Estado do Rio de Janeiro (ERJ) no contexto político do ano de 2003. Ressalta-se que a escolha das ADI tem relação com o fato de ambas estarem concluídas e disponíveis ao público.

Seguimos as sugestões metodológicas de Vianna e Burgos15 de analisar os processos judiciais a partir de quatro passos: 1) a análise dos antecedentes do processo; 2) a análise da sustentação jurídica; 3) o acompanhamento da construção da decisão; e, 4) a avaliação da efetividade da decisão. Soma-se a isso a necessidade de identificar se a atuação do STF propulsiona o trabalho no legislativo (POGREBINSCHI, 2011), o que já anunciamos como pressuposto desse trabalho, haja vista a própria LC 141.

Além disso, o tratamento do material empírico foi feito com base na teoria da análise da retórica, conforme proposta por Perelman e Olbrechts-Tyteca (1996). Para estes autores "é em função de um auditório que qualquer argumentação se desenvolve" (idem, p.6). Entendemos, no caso analisado, que os Ministros do Supremo se constituem como o auditório privilegiado o qual busca-se convencer. Estes autores defendem que a argumentação jurídica é um gênero próprio e específico, ele "se refere a avaliações sobre a natureza e a causa de eventos passados, em que diversas estratégias de convencimento são utilizadas" (idem, p.53). Contudo, apesar de ser próprio do Poder Judiciário esse olhar para o passado, não podemos perder de vista os efeitos práticos da argumentação desenvolvida nessas ADI, "voltada para o futuro, ela se propõe provocar uma ação ou preparar para ela, atuando por meios discursivos sobre o espírito dos ouvintes" (idem, p. 53). O estudo desses dados indicou que grande parte das ADI ajuizadas se voltava não apenas para a discussão da saúde e das políticas de saúde, mas para as questões referentes às atribuições de cada ente federado. Isto permitiu selecionar algumas ADI para estudo aprofundado. Ressalta-se que no site do STF constam apenas as petições iniciais, o andamento e as decisões. $\mathrm{O}$ acesso físico às ADI, ou seja, ao inteiro teor dos votos e dos pareceres, é possível apenas após a conclusão do processo, quando estas deixam os gabinetes dos Ministros e são encaminhadas para o arquivo do STF. 
A literatura (VIANNA et al, 1999; CASTRO, 1997; PACHECO, 2008; TAYLOR, 2007; TAYLOR e DA-ROS, 2008) tem demonstrado que a análise das ADI vem sendo feita exclusivamente sob o enfoque quantitativo. A perspectiva adotada neste trabalho visa aprofundar as questões presentes nas ADI com o tema específico da saúde, o que foi feito a partir de um enfoque qualitativo, por meio da análise da retórica. Foram selecionadas duas ADI (2999 e 3088) que dizem respeito à interpretação do conceito de saúde e a consequente alocação de recursos financeiros nesta área, ambas originadas no Estado do Rio de Janeiro (ERJ) no contexto político do ano de 2003. Ressalta-se que a escolha das ADI tem relação com o fato de ambas estarem concluídas e disponíveis ao público.

Seguimos as sugestões metodológicas de Vianna e Burgos15 de analisar os processos judiciais a partir de quatro passos: 1) a análise dos antecedentes do processo; 2) a análise da sustentação jurídica; 3 ) o acompanhamento da construção da decisão; e, 4) a avaliação da efetividade da decisão. Soma-se a isso a necessidade de identificar se a atuação do STF propulsiona o trabalho no legislativo (POGREBINSCHI, 2011), o que já anunciamos como pressuposto desse trabalho, haja vista a própria LC 141.

Além disso, o tratamento do material empírico foi feito com base na teoria da análise da retórica, conforme proposta por Perelman e Olbrechts-Tyteca (1996). Para estes autores "é em função de um auditório que qualquer argumentação se desenvolve" (idem, p.6). Entendemos, no caso analisado, que os Ministros do Supremo se constituem como o auditório privilegiado o qual busca-se convencer. Estes autores defendem que a argumentação jurídica é um gênero próprio e específico, ele "se refere a avaliações sobre a natureza e a causa de eventos passados, em que diversas estratégias de convencimento são utilizadas" (idem, p.53).

\section{ANÁlise dOS ANTECEDENTES DAS ADI}

Após a promulgação da Lei n. 8.080 de 1990 (Lei Orgânica da Saúde) o país vivenciou um período de incertezas quanto ao financiamento do SUS (PAIVA \& TEIXEIRA, 2014). Apenas a partir de 1999, com a Emenda Constitucional 29 (EC 29), foi definido um percentual mínimo a ser gasto com o setor saúde, o que, no entanto, trouxe outros impasses para o campo da gestão pública da saúde pois, afinal, não havia especificação legal sobre o conceito de 'saúde'. Tal impasse passou a ser levado aos tribunais. Apenas a partir da LC 141 que a gestão passou a ter alguma referência legal sobre o conjunto de ações e serviços de saúde que podem ser financiados com o orçamento da saúde. Antes disso, havia um vazio normativo referente aos itens financiáveis no âmbito do Fundo de Saúde.

Se a década de 1990 ficou marcada como um período de desfinanciamento da saúde (sobretudo após a extinção do Inamps em 1993), a partir dos anos 2000, com a aprovação da EC 29 a questão passa a ser a destinação destes gastos. De alguma 
forma, a pergunta “o que é saúde?" volta ao cenário público, não mais pela necessidade de sua ampliação, mas, ao contrário, pela necessidade de sua redução.

Se, durante quase meio século, discutiu-se o ideal de saúde, parece que agora o Brasil tem uma preocupação bem diferente: como materializar este ideal com os recursos existentes? Tal preocupação traz ao cenário público a definição coletiva de prioridades. Este papel pode ser desempenhado pelos conselhos e conferências de saúde dos municípios e estados brasileiros, conforme previsto na Lei n. 8.142/1990. Desta forma, diante do vazio normativo em 2003 o Conselho Nacional de Saúde (CNS) chamou para si a responsabilidade de dizer "o que é saúde" e editou a Resolução n. 322, que definia em que poderiam ser gastos os recursos do fundo de saúde. Tal resolução fez com que o governo do ERJ ajuizasse a ADI 2999.

O CNS, ao editar a Resolução n. 322, reconhece a plenitude do conceito de saúde, mas optou por privá-lo de parte de seus condicionantes e determinantes por questões de financiamento. $\mathrm{O}$ conflito envolvido ao redor de tal Resolução deve-se a uma suposta invasão nas competências legislativas dos Estados, o que, pela interpretação da governadora do ERJ, feriu a autonomia estadual.

\subsection{HiSTÓRICO DO CONFLITO POLÍTICO DE 2003}

No final do ano de 2002 a então governadora do RJ, Benedita da Silva, vetou projeto que autorizava a criação do Fundo de Erradicação e Combate à Pobreza e Desigualdades Sociais (FECP) no Estado do Rio de Janeiro, que seria iniciado no exercício fiscal de 2003 e iria até o ano de 2010. Este Projeto de Lei previa, sobretudo, o aumento das alíquotas do ICMS visando o custeio de programas sociais. Benedita da Silva ocupou o cargo de Governadora por oito meses, era Vice-Governadora na Gestão de Antony Garotinho que se desvinculou do cargo para concorrer à Presidência da República. No fim do ano de 2002 o resultado para as eleições já havia sido informado: a candidata Rosinha Garotinho havia ganhado as eleições no Rio de Janeiro e sucederia Benedita da Silva na gestão estadual. (GERSCHMAN \& SANTOS, 2016)

De posse do resultado das eleições, a Assembleia Legislativa do Rio de Janeiro (Alerj) passou a trabalhar em regime de urgência para aprovar leis que seriam necessárias para a continuidade do modelo de gestão e relacionamento com as camadas mais pobres da população, adotadas desde o governo de Antony Garotinho (marido da então Govenadora eleita). Um desses projetos era a aprovação do Projeto Legislativo n. 3.413-A/2002. A Alerj discutiu e aprovou este projeto e encaminhou para sanção ainda na gestão de Benedita da Silva, que, para não ficar com o custo político de um projeto de aumento de impostos, o vetou integralmente.

O veto foi derrubado no dia 30 de dezembro do mesmo ano numa sessão extraordinária da Alerj e o referido projeto tornou-se a Lei n. 4.056 de 2002. No ano seguinte, dado o ajuizamento de duas ADI (ADI 2845 e ADI 2869) questionando a constitucionalidade dessa Lei, a já governadora Rosinha Garotinho sancionou a Lei 
n. 4.086/2003 que alterou apenas a forma de escrita dos artigos da Lei n. 4.056, mas não seus significados. A principal mudança foi substituir o seguinte trecho do artigo 10: "recursos serão aplicados em ações suplementares de nutrição, habitação, educação, saúde, reforço da renda familiar, saneamento e outros programas de relevante interesse social, voltados para a melhoria de qualidade de vida", por "visando a melhoria de qualidade de vida". Essa mudança na redação não alterou o sentido que o Fundo tem, mas ampliou o leque de possibilidades de investimento do Estado. Tal legislação antecipou os efeitos da EC n. 42, aprovada em dezembro de 2013, que passou a permitir que os Estados adotassem tal medida.

Em 2003, segundo os dados da Secretaria de Estado de Fazenda do RJ, a arrecadação do Imposto sobre circulação de mercadorias e serviços - ICMS (principal imposto Estadual) aumentou cerca de 950 milhões de reais, tendo sido de mais de treze bilhões de reais o total de recursos arrecadados pelo Estado neste ano. Pelas regras da EC 29, o Rio de Janeiro teria como obrigação financeira aplicar pelo menos 10,29\% desses recursos com saúde. De acordo com dados do SIOPS, neste ano o ERJ investiu 10,99\% da arrecadação com saúde, ou seja, mais do que o exigido constitucionalmente. Contudo, estudo realizado por Campelli e Calvo (2007) mostrou que o RJ investiu em saúde em 2003 apenas 8,04\% do orçamento total. Esta diferença se deve à interpretação sobre utilização dos recursos do Fundo Estadual de Saúde, como discutiremos mais à frente.

Dois meses após a criação do FECP no RJ, o CNS editou a Resolução n. 322/2003 que visava dirimir dúvidas quanto aos gastos que poderiam ser categorizados como "gastos em saúde". A Sétima Diretriz desta Resolução determina que, para efeito da aplicação da EC 29, não são consideradas como despesas com ações e serviços públicos de saúde as relativas a: "pagamento de aposentadorias e pensões"; "assistência à saúde que não atenda ao princípio da universalidade"; "merenda escolar"; "saneamento básico (...) ainda que excepcionalmente executado pelo Ministério da Saúde, pela Secretaria de Saúde ou por entes a ela vinculados"; "ações de assistência social (...) não promovidas pelos órgãos de Saúde do SUS".

As limitações de gasto presentes na Resolução n. 322 iam de encontro às necessidades políticas do RJ que aprovaria a seguir duas leis que feririam frontalmente os princípios dispostos nesta Resolução. Por este motivo, a Governadora do RJ ajuizou a ADI 2999 contestando a legitimidade discricionária do CNS (BRAGHIN, 2017). Buscava, sobretudo, a impugnação do inciso IV da Sétima Diretriz da Resolução.

Esta ADI tramitou por cinco anos e oito meses até receber uma decisão final, tendo oito volumes com duas mil páginas ao total. Nela estão presentes os posicionamentos do Governo Federal, do Poder Executivo e da Assembleia Legislativa do RJ, além de diversos setores da sociedade civil, conforme previsto pelo instituto jurídico do Amicus Curiæ, que permite a participação no processo de pessoas e instituições que tenham comprovada identidade com o caso examinado pelo tribunal (MACHADO, 2010; COSTA, 2012). 
Neste caso específico, trata-se da interpretação do conceito de saúde e da legitimidade de atuação do CNS. Mais que isso, no ano de 2003, foram realizadas diversas ações e editadas algumas normas voltadas justamente para a questão da interpretação do conceito de saúde. Desta forma, o governo do RJ chamava para si a responsabilidade e autonomia presentes no pacto federativo de definir os rumos de suas políticas sociais, estabelecendo, com isso, as bases do que considerava como legítimo ou não nas políticas setoriais da saúde. Tal legitimidade foi, ao mesmo tempo, contestada e requerida no STF. A ADI 2999 é mais uma tentativa de reconhecimento e esclarecimento, pelo Tribunal Constitucional, das atribuições e da autonomia dos Estados.

Quatro dias após ajuizar a ADI 2999, o RJ aprovou a Lei n. 4.167/2003 que "autoriza o poder executivo a instituir no orçamento de 2003, programas de trabalho no Fundo Estadual de Saúde (FES)". O atendimento dessas despesas seria custeado por um crédito de $25 \%$ do total de recursos do FES e incluía, dentre outros, "os seguintes programas de trabalho: farmácia popular; ações de saneamento básico; suplementação alimentar; saúde na terceira idade; cheque saúde cidadão; alimentação escolar nas férias e apoio aos serviços de saúde do Corpo de Bombeiros".

Três dias depois foi aprovada a Lei n. 4.179/2003 que dispunha "sobre a instituição do programa estadual de acesso à alimentação (PEAA)". Seu artigo $2^{\circ}$ previa que "os benefícios financeiros decorrentes do PEAA serão efetivados através da distribuição de cupom, cheque, cartão ou outro instrumento próprio, ou pelo acesso a alimentos preparados ou em espécie pelas famílias em situação de insegurança alimentar, (...)".

$\mathrm{O}$ artigo $5^{\circ}$ esclarece que "o atendimento aos projetos e atividades integrantes do PEAA correrá à conta de dotações consignadas anualmente ao orçamento do FES, vinculado à Secretaria de Estado de Saúde". Após a edição destas Leis Estaduais, o Partido da Social-Democracia Brasileira (PSDB) do ERJ ingressou com a ADI 3087 (impugnando a Lei n. 4.179) e com a ADI 3088 (impugnando a Lei $n$. 4.167).

Quando somados os recursos da exigência da EC 29 para o ano de 2003 no RJ com os recursos do adicional de ICMS arrecadado para compor a FECP, tinha-se um total de $\mathrm{R} \$ 2.281 .342 .323,00$ (mais de dois bilhões de reais) de recursos próprios do Estado (fora as transferências da União vinculadas à saúde) para financiar o combate à pobreza, programas de trabalho, programas de alimentação e toda a saúde do ERJ. No entanto, o que se observou não foi a soma desses gastos, mas a sobreposição de uma rubrica em outra, ou seja, o governo do RJ utilizou os recursos do FECP para fins de cumprimento da EC 29. Segundo Campelli e Calvo (2007) muitos Estados indicaram o cumprimento da EC 29 incluindo "gastos considerados alheios à saúde, tais como as despesas com inativos, com saneamento, habitação urbana". 


\section{ANÁlise DA SUSTENTAÇÃo JURÍDICA E CONSTRUÇÃo DA DECISÃO}

\subsection{ADI 2999}

Na petição inicial da ADI 2999, o Governo do ERJ afirma que a edição da referida Resolução seria um típico caso de inconstitucionalidade formal, pois "é ato normativo natimorto sob a perspectiva constitucional, tendo em vista que as normas por ela veiculadas foram reservadas pelo Constituinte à regulamentação pela via da Lei Complementar". Esta contestação diz respeito à legitimidade do CNS na edição de normas como esta, que seria atribuição exclusiva dos legisladores federais por via de Lei Complementar.

Outro conjunto de argumentos abarca os aspectos materiais da Resolução n. 322, ou seja, contesta-se seu conteúdo. Em primeiro lugar, a Governadora alega que a proibição de se gastar recursos do FES com saneamento básico vai de encontro ao que regulamenta o art. 79 do Ato das Disposições Constitucionais Transitórias (ADCT) da Constituição da República "que, inclusive, expressamente indica a possibilidade de destinação desses recursos com ações suplementares de saúde". O início de sua argumentação cria um elo direto entre ações suplementares de saúde e saneamento básico.

Na sequência, a autora defende a ideia de que a Resolução n. 322 invade a competência legislativa dos Estados-membros, pois regular a forma como cada Estado gasta o dinheiro é tarefa intrínseca dos governos locais. Por este motivo, a Governadora ressalta nesta ADI a autonomia dos Estados: "não poderia órgão federal diverso do Congresso Nacional, sem legitimidade constitucional para tanto, oferecer normas suplementares em lugar dos Estados-membros, ainda que a pretexto de conferir aplicabilidade a dispositivos da Constituição".

Desta maneira, o Governo do ERJ reafirmou a competência residual para os assuntos administrativos. Este argumento, no entanto, desconsidera as vinculações orçamentárias para as áreas da saúde e da educação. Sobre isto, a autora sustenta que "a Resolução 322 inibe o Estado do Rio de Janeiro de estabelecer e manter, com a autonomia garantida pela Constituição da República, políticas sociais e econômicas preventivas em defesa da saúde da população fluminense". Além disso, a autora assevera que não existe Federação sem que se reserve aos Estados-membros um conjunto de competências que lhes garanta autonomia, em sua tríplice dimensão: administrativa, legislativa e política. Desta forma, a Resolução do CNS feriria os princípios da separação dos poderes.

Na sequência da retórica presente na petição inicial a autora contesta a exclusão do cálculo do FES os gastos com recursos do Fundo de Combate e Erradicação da Pobreza, pois "se o próprio art. 79 do ADCT revela que os recursos do Fundo de Combate e Erradicação da Pobreza podem ser utilizados em medidas e programas de defesa da saúde, não poderia mera Resolução dispor contrariamente, impedindo o Estado-membro de computar a receita utilizada, sob esta rubrica, para atendimento aos limites mínimos constitucionais". 
A compreensão dessa contestação pode ser encontrada no conjunto de leis editadas no ano de 2003 pelo governo do Estado do RJ. Conforme comentado, o ERJ arrecadou, neste ano, por volta de treze bilhões de reais, já incluídos os mais de novecentos milhões de reais do acréscimo de ICMS via FECP. Ora, o que fez a governadora do Estado do RJ? Computou esta arrecadação extra como sendo para área da saúde (investimento em saneamento básico), ultrapassando com isto o mínimo estabelecido pela EC n. 29.

A justificativa para este artifício deve-se, novamente, à certeza de que o saneamento básico é uma ação de saúde. Além disso, a governadora já utilizava os recursos do FES para financiar ações de combate à fome (como os Restaurantes Populares e o Cheque Cidadão).

\begin{abstract}
“De seu lado, o art. 200 da Constituição da República, ao tratar das atribuições do SUS, inclui, entre estas, a formulação de políticas e a execução de ações de saneamento básico e de vigilância sanitária. Logo, a própria Constituição reconhece no saneamento básico elemento determinante à boa saúde da população, o que torna irrazoável a exclusão perpetrada pela Resolução 322".
\end{abstract}

A Governadora conclui seu argumento afirmando que se a Resolução n. 322 for considerada constitucional, estar-se-ia não apenas limitando a autonomia dos Estados, mas, no caso do ERJ, justificando uma intervenção federal.

O relator da ADI, Ministro Gilmar Mendes, expediu ofício ao Ministério da Saúde (MS) para manifestar-se em relação às alegações da autora. O MS defende a Resolução n. 322, por entender que ela é fundamental para o esclarecimento na condução das políticas de saúde no país. O primeiro argumento do Ministério da Saúde afirma que o ajuizamento desta ADI é inútil, na medida em que existe uma portaria ministerial (Portaria n. 2.047/2002GM) que dispõe igualmente do assunto tratado. Assinada pelo Ministro Barjas Negri, em novembro de 2002, esta portaria prevê o mesmo que consta na Resolução n. 322: que o saneamento básico não poderia ser considerado como despesa da saúde.

Para o MS, a Resolução não invadiria a competência legislativa dos Estados, pois suas diretrizes visavam "instrumentalizar, estabelecer regras de execução de comando constitucional que já é eficaz, autoaplicável, qual seja, o insculpido no art. 77 do ADCT, com redação determinada pela EC n. 29/2000". Suas diretrizes "esclarecem, apenas. Nada ampliam nem inovam".

O parecer do MS visa elucidar a correta interpretação sobre o Fundo de Combate e Erradicação da Pobreza. No parecer, reafirma-se que estes "recursos serão aplicados em ações suplementares...", conforme art. 79 da ADCT. Segue-se a isso uma interpretação sobre o significado do termo "suplementares".

O MS argumenta que "suplementar" indica ir além do que é ordinariamente executado. "O objetivo do legislador foi o de acrescentar receitas para aplicação em saúde", 
não podendo, portanto, financiar obrigações ordinárias. "Alimentação e saneamento básico foram eleitos como fatores determinantes ou condicionantes da saúde (...). Esses elementos, conquanto sejam determinantes, não compõem atividades finalísticas que se pode denominar 'ações de saúde'".

Nas páginas seguintes do processo encontra-se o parecer da Advocacia Geral da União (AGU), que afirma que "a lei 8080 não define as ações de saneamento básico como "ações de saúde", não sendo possível que a Governadora-requerente alargue o conceito desta espécie de atividade sem violar o disposto no artigo 30 da referida legislação".

O Procurador-Geral da República (PGR) concorda com a AGU e volta-se para o esclarecimento do significado de uma Resolução, que não teria a função de criar uma Lei, mas apenas de elucidá-la, sendo, portanto, atribuição intrínseca ao CNS. De certa forma, esta procuradoria defende a legitimidade do CNS nesta disputa, mas não defende o mérito da norma, sugerindo apenas que não é pertinente a proposição de uma ADI.

Interessante destacar que nenhum parecer emitido pelas instituições consultadas enfatizou a importância do CNS ou defendeu a legitimidade da Resolução n. 322. Entretanto, posicionavam-se favoravelmente ao mérito desta norma em função da existência de uma portaria do MS de idêntico teor. Posição diferente a esta foi adotada pelos Amicus Curix. Apenas estes expressaram a importância política desta ADI, enquanto os outros se detiveram nas questões meramente jurídicas. Desta forma, os setenta e quatro convocados como Amicus Curiz pediram unanimemente ao STF "o reconhecimento de competência deliberativa do CNS e a declaração da constitucionalidade da Resolução 322". As argumentações presentes neste Amicus Curize indicam que, se fosse declarada a inconstitucionalidade da Resolução, o próprio conselho estaria ameaçado.

Em março de 2008 foi proferida a sentença da ADI 2999. Para o Ministro Gilmar Mendes, não se tratou de questionar a legitimidade do CNS, entendendo justificarse a atuação do CNS no âmbito das normatizações voltadas para a gestão do SUS. Para este Ministro, o equívoco reside na escolha da ADI como mecanismo de contestação, pois "nesse contexto, resta evidenciado que, no caso, o exame da legitimidade do ato do CNS passa, antes de uma análise constitucional, por uma aferição de compatibilidade com esse complexo normativo infraconstitucional". Portanto, o voto do Relator foi pelo não conhecimento da ADI. Todos os Ministros acompanharam o voto do relator, com exceção do Ministro Marco Aurélio, que votou pela procedência da ADI. Para ele, a falta de Lei Complementar que disciplinasse a EC n. 29 gerou uma lacuna legal, que "veio a ser preenchida, em via imprópria, pelo Conselho Nacional de Saúde". O Ministro reafirma a centralidade do Congresso no preenchimento dessas lacunas.

$O$ voto vencedor nesta ADI tenta se afastar de querelas com os outros poderes e, de certa forma, reconduz a discussão para o cenário público, embora o relator tenda a aceitar a posição do CNS como articulador das relações federativas no âmbito da saúde. 


\subsection{ADI 3088}

Quatro dias após o ajuizamento da ADI 2999, a Governadora do RJ sancionou a Lei n. 4.167/2003 (lei que autoriza a criação dos programas de trabalho no âmbito do orçamento do FES). Três meses depois, em dezembro de 2003, o PSDB ajuizou ADI impugnando esta lei com pedido de liminar para a suspensão imediata dos seus efeitos. A liminar não foi concedida e o processo tramitou por um ano e quatro meses, vindo a ter seu seguimento negado pela perda de objeto, já que se tratava de lei com efeitos exauridos.

É pertinente indagar, neste sentido, o que teria levado um partido político de oposição a requerer a declaração de inconstitucionalidade de uma lei 18 dias antes de sua validade expirar? Parece plausível supor que se esteja diante da opção de atuação política descrita por Vianna et al (1999) de declarar publicamente repúdio à norma por outros meios que não os tradicionais no Legislativo e no Executivo. Conforme argumentam Ribeiro e Arguelhes $(2019$, p.3) "a decisão de mobilizar o Supremo é uma ação estratégica que emerge do jogo político do momento"; é, "parte importante da variação do que será objeto de contestação judicial, quem acionará o STF e como, quando e quanto o tribunal será mobilizado é explicada por fatores que são contingentes à dinâmica política".

Taylor e Da-Ros (2008, p.827) argumentam que "as táticas judiciais (...) não estão necessariamente assentadas na expectativa de uma vitória judicial", podem, por exemplo, buscar na arena judicial benefícios políticos ao angariarem "em torno de si considerável atenção pública, decorrente em especial da visibilidade que os meios de comunicação dedicam a esses episódios" (idem).

Cabe destacar que, embora essa legislação tivesse um prazo de vigência de apenas três meses, desde o ano anterior o governo do ERJ já incluía entre as despesas de saúde as ações descritas. É possível que esta lei tenha sido uma resposta do ente federado tanto à edição da Portaria n. 2.047/02 do MS quando da Resolução n. 322 do CNS.

A argumentação do PSDB era de que no ano de 2002 as contas do Estado haviam sido rejeitadas pelo Tribunal de Contas do Estado justamente pela computação no âmbito da FES de ações semelhantes ao previsto na referida lei e que o Estado havia suprimido da saúde cerca de "sessenta e um milhões de reais gastos em programas da mesma natureza que o Programa Estadual de Acesso à Alimentação e indevidamente apresentados como sendo aplicações em ações e serviços de saúde"

A manobra jurídica presente na edição da referida lei no ERJ foi possível pois inexistia em âmbito federal legislação que disciplinasse detalhadamente como deveriam ser gastos os recursos da saúde. A edição da Lei n. 4167/03 significou uma disputa entre uma unidade territorial e uma instância do SUS - o CNS -, pela legitimidade de edição de normas. O ERJ reafirmou sua autonomia como ente federado e chamou a si a responsabilidade pela competência residual. 
O PSDB optou por questionar o mérito da legislação, apontando as incoerências inconstitucionais quanto aos gastos do FES. Para este partido, o estabelecimento das ações e serviços considerados como de saúde já está presente na Lei federal $\mathrm{n}$. 8.080/1990. Como desdobramento, a petição inicial enfatiza que o saneamento básico não poderia ser considerado como ação de saúde. Este é o ponto crucial para o governo do ERJ, que, na ADI 2999 requereu do STF interpretação que legitimasse este tipo de gasto no orçamento da saúde.

A defesa do RJ na ADI 3088 inicia-se com a proposta de que esta tramite conjuntamente com a ADI 2999. Este pedido vislumbrava, sobretudo, buscar apoio das instâncias federais para a interpretação de que o recurso do FES poderia ser gasto com saneamento básico. Ressalta-se que esta ação configura uma disputa política estabelecida entre um partido de oposição ao governo central e um partido integrante da base aliada deste governo ${ }^{5}$.

Chama a atenção na análise dos pareceres a posição dúbia tanto da AdvocaciaGeral da União (AGU) quanto da Procuradoria-Geral da União, que, nos pareceres dado à ADI 3088, defendiam as razões da Governadora Rosinha, mas no caso da ADI 2999, de igual conteúdo, defendiam a posição do Governo Federal representado pelo Ministério da Saúde. A explicação para esse fenômeno está na teoria proposta por Perelman e Olbrechts-Tyteca (1996) de que a argumentação se volta para o convencimento do auditório, não necessariamente carrega consigo noções sólidas sobre determinada situação ou até mesmo verdades. Além disso, a análise do conteúdo retórico-argumentativo presente nas ADI evidencia que a linguagem do direito, muitas vezes tida como técnica e asséptica para os que estão de fora, é manejada pelos diversos atores de forma a justificar opções políticas, camuflando essas opções sob o manto da própria linguagem hermética (BOURDIEU, 2000).

A AGU afirma, na ADI 3088, que as ações de saneamento básico podem ser consideradas como ações de saúde e na ADI 2999 afirma que "a lei 8080, não define as ações de saneamento básico como "ações de saúde", não sendo possível que a Governadora-requerente alargue o conceito desta espécie de atividade sem violar o disposto no artigo 30 da referida legislação". No caso da ADI 3088, o Réu é o Governo do ERJ, que, no início de 2003, era dirigido pelo PSB, partido da base aliada do governo Lula, e, à época desta ADI, era governado pelo então Partido do Movimento

\footnotetext{
${ }^{5}$ A expressão 'base aliada' se justifica pelo fato do candidato à Presidência da República Antony Garotinho, que no $1^{\circ}$ turno das eleições conquistou $17 \%$ dos votos válidos, ter apoiado no segundo turno o candidato do PT, Lula, que venceu o candidato Serra (PSDB) com 61,3\% dos votos. Além disso, a expressão 'base aliada' também se deve pela composição ministerial. Logo no início de sua gestão, Lula indicou Roberto Amaral (nome histórico do PSB) para o Ministério de Ciência e Tecnologia.

A governadora Rosinha trocou o PSB pelo PMDB em agosto de 2003, e, de fato, o PMDB só veio a integrar o primeiro escalão do governo Lula no ano seguinte, mas esta costura vinha sendo feita pelo menos desde meados de 2003.
} 
Democrático Brasileiro (PMDB e hoje MDB), partido ainda mais forte da base do governo Lula.

A postura adotada pela AGU nesta ADI foi de defesa incondicional do mérito da Lei, embora também faça uma defesa da forma. Inicialmente afirma que "ao autorizar a criação de programas de trabalho no âmbito do Orçamento do FES (...) revestese, inequivocamente, da natureza jurídica de lei orçamentária". Assim, a AGU defende o não cabimento de $A D I$ "tendo em vista cuidar-se de lei tão-somente em sentido formal, porque, materialmente, detém conteúdo de ato administrativo, de efeitos concretos". Além disso, prossegue a AGU, "a definição das bases conceituais para a operacionalização e o cumprimento do que determina o art. 77, do ADCT, é tarefa do agente político encarregado de estabelecer e implementar política nacional de saúde no país, nos termos da legislação vigente", portanto, "os Programas de Trabalho a serem criados pelo Governador do Estado do Rio de Janeiro, atendem aos fatores determinantes e condicionantes da saúde", caracterizando-se, desta forma, como serviços de saúde.

Fica evidente, portanto, não a defesa irrestrita de um princípio jurídico de forma 'técnica', como o Campo do Direito (BOURDIEU, 2006) tenta sempre se apresentar, mas uma hermenêutica voltada para a defesa política dos interesses do Governo. No caso da ADI 2999, a AGU seguia as recomendações do MS. Na ADI 3088, defendia os interesses da aliança política do governo central.

Como os efeitos da legislação a qual se referia a ADI 3088 visavam apenas o ano de 2003, o Ministro Relator, Marco Aurélio - mesmo ministro que votou a favor da ADI 2999 -, negou seguimento à ação, sem entrar na discussão central do mérito da ADI. A tentativa desta Corte de não atuar diretamente em determinados conflitos de natureza política pode ser interpretada como um repúdio à judicialização ao menos na área da saúde. De acordo com Pacheco (2008) a estratégia de levar ao arquivamento da ação permite que o STF "resolva tanto os casos difíceis, ou, como se verifica aqui, um conjunto relativamente expressivo de ações, de modo a evitar a abertura de precedentes que comprometeriam a coerência da ordem jurídica e da jurisprudência do Tribunal".

\section{CONCLUSÃO}

O conflito jurídico-normativo aqui relatado traz à tona a necessidade de olharmos atentamente para os seus aspectos políticos inerentes. A análise do conjunto de leis editadas no ERJ evidencia um conflito entre a oposição política e o governo de situação que, embora discutindo aspectos locais, extrapolou o ERJ tendo importante repercussão política nacional. Neste contexto, destaca-se a tentativa do CNS de afirmar-se como força institucional capaz de interferir nos rumos da administração pública em saúde no Brasil. Pelo resultado da ADI 2999, o CNS não teve seu poder negado, mas abalado, dado que o governo do ERJ não foi obrigado a se sujeitar a esta Resolução, ressaltando os aspectos da autonomia estadual. 
Neste permanente cabo de guerra que é o federalismo, o chamado à judicialização trouxe poucas conclusões, mas talvez tenha proporcionado um rearranjo das forças políticas, pois a resposta do STF nem deslegitimou os gastos do Estado do RJ e nem legitimou a ação discricionária do CNS. Assim, se havia um tênue consenso sobre as atribuições do CNS e do próprio MS, os resultados das ADI podem indicar um novo patamar de discussões. Mais que isso, podem indicar que o campo de disputas está completamente aberto e que novos arranjos podem ser gerados, inclusive com assunção de espaços de diálogo e consenso, como seria o CNS.

Um dos efeitos desta disputa foi a mobilização do Legislativo e do Executivo que se movimentaram e rapidamente aprovaram a LC 141, que em seu artigo $3^{\circ}$ define quais despesas com ações e serviços públicos de saúde podem ser computados no orçamento da saúde. O inciso IV deste artigo dirime qualquer dúvida sobre a questão do saneamento básico, pois permite gastos nestas ações desde que "seja aprovado pelo Conselho de Saúde do ente da Federação financiador da ação e esteja de acordo com as diretrizes das demais determinações previstas nesta Lei Complementar".

Importante ressaltar que a LC 141 devolve aos Conselhos aquela responsabilidade requerida pelo CNS na Resolução n. 322, na medida em que são estes que, agora, devem analisar o caso a caso da gestão local e decidir sobre a pertinência de se compreender o saneamento básico como uma ação de saúde.

Embora no caso da ADI 2999, tanto o Governo Estadual, quanto o CNS (e todas as instâncias que se pronunciaram através do Amicus Curiæ) esperassem uma resposta concreta do STF, não é possível negar o fato de que, por meio do chamamento do Judiciário, tanto Legislativo quanto Executivo, e, sobretudo, a própria sociedade civil foram levadas a se manifestar sobre o tema em questão. Desta forma, o Supremo não deixou de atuar como árbitro. Tratou-se de uma maneira de politizar a questão, jogando-a de volta para o debate público. 


\section{FIGURA 1 - LINHA DO TEMPO}

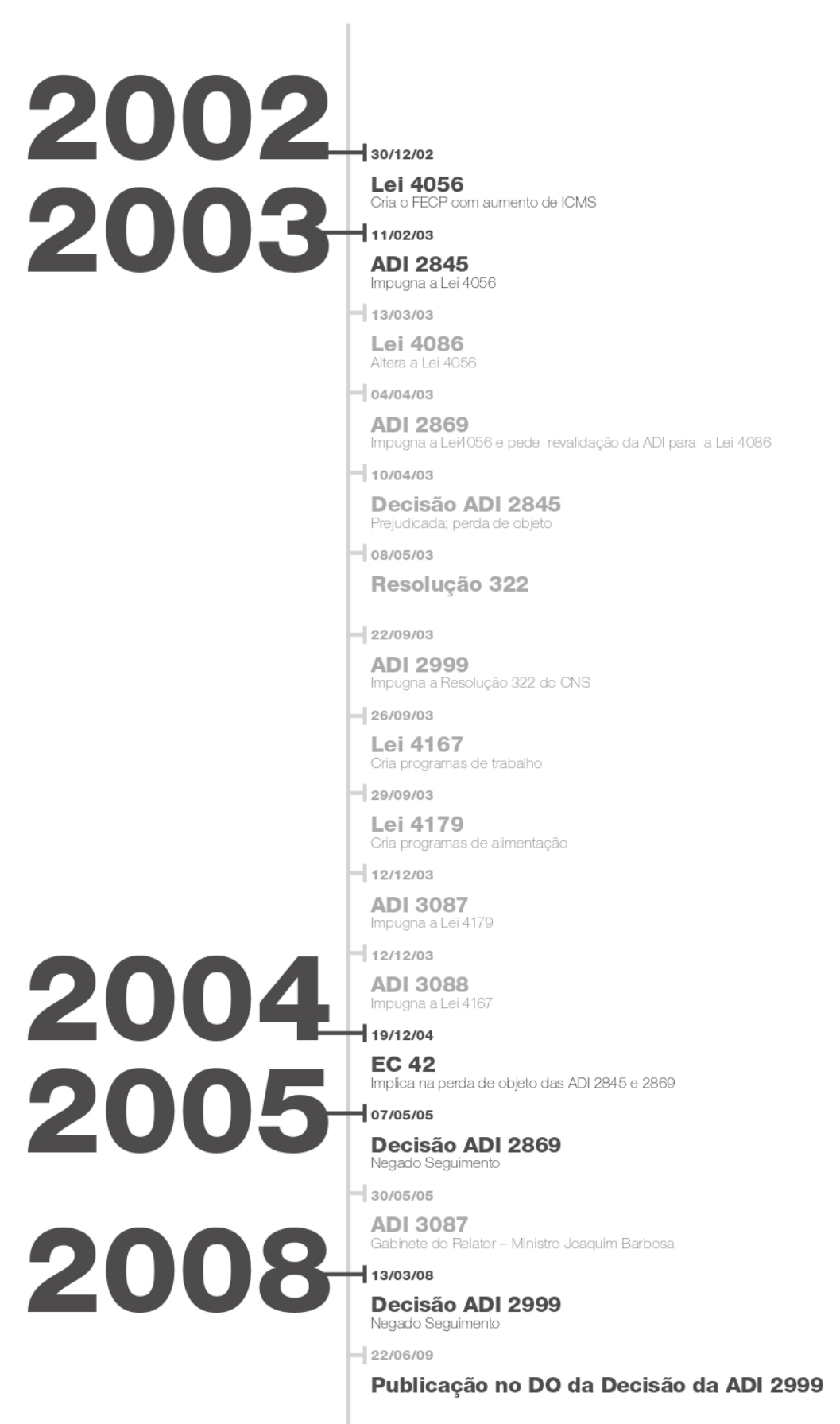




\section{REFERÊNCIAS}

ARRETCHE, Marta. Federalismo e políticas sociais no Brasil: problemas de coordenação e autonomia. São Paulo Perspec, v.18, n.2, p. 17-26, 2004.

ARRETCHE, M. Democracia, federalismo e centralização no Brasil. Rio de Janeiro: Fundação Getúlio Vargas/Fiocruz, 2012.

BAPTISTA, Tatiana Wargas de Faria; MACHADO, Cristiani Vieira e LIMA, Luciana Dias de. Responsabilidade do Estado e direito à saúde no Brasil: um balanço da atuação dos Poderes. Ciênc. saúde coletiva, v.14, n.3, pp. 829-839, 2009.

BOURDIEU, Pierre. O poder Simbólico. Rio de Janeiro: Bertrand Brasil, 2006.

BRAGHIN, Simone. Sociedade Civil no Supremo: avanço de uma agenda de direitos? 2017.153 f. Dissertação (Mestrado) em Sociologia da Universidade Federal de São Carlos.

CAMPELLI, Magali Geovana Ramlow; CALVO, Maria Cristina M. O cumprimento da Emenda Constitucional no 29 no Brasil. Cadernos de Saúde Pública, v. 23, n. 7, p.1613-1623, 2007.

CASTRO, Marcus F. O Supremo Tribunal Federal e a judicialização da política. Revista Brasileira de Ciências Sociais, v.12, n. 34, 1997.

CEBES. "A Questão Democrática na Área de Saúde", Revista Saúde em Debate no 9, jan/fev/mar, RJ, 1980, pp 11- 13.

COSTA, Beatriz Castilho. A influência exercida pelo amicus curiae nos votos dos ministros do Supremo Tribunal Federal nos acórdãos das ações direta de inconstitucionalidade decididas majoritariamente, 2012. 115 f. Dissertação (Mestrado) Escola de Direito do Rio de Janeiro da Fundação Getúlio Vargas. Orientadora: Fabiana Luci de Oliveira. Co-orientador: Leandro Molhano Ribeiro.ELAZAR, Daniel. Exploring federalism. Tuscaloosa, AL: University of Alabama, 1987.

ESPING-ANDERSEN, Gosta. As três economias políticas do welfare state. Lua Nova, São Paulo, n. 24, p. 85-116, Sept. 1991. http://dx.doi.org/10.1590/S010264451991000200006FAGNANI, E. Política Social e Pactos Conservadores no Brasil: 1964/1992. Economia e Sociedade (UNICAMP), v. 8, p. 183-238, 1997. 
GERSCHAMN, S.; SANTOS, A. M. S. P. Saúde e Políticas Sociais no Rio de Janeiro. Rio de Janeiro: Editora Fiocruz, 2016. 262p.

MACHADO, Felipe Rangel de Souza. A judicialização da saúde no Brasil: cidadanias e assimetrias - 2010. 185f. Orientadora: Sulamis Dain. Tese (doutorado) - Universidade do Estado do Rio de Janeiro, Instituto de Medicina Social.

PACHECO, Cristina Carvalho. Supremo Tribunal Federal e a Reforma do Estado: as Ações Diretas de Inconstitucionalidade (Adins) julgadas no primeiro mandato do Governo Fernando Henrique Cardoso (1995-1998). 6 a ABCP - Conferência da Associação Brasileira de Ciência Política, Unicamp, Campinas, SP, julho de 2008.

PAIVA, Carlos Henrique Assunção; TEIXEIRA, Luiz Antonio. Reforma sanitária e a criação do Sistema Único de Saúde: notas sobre contextos e autores. História, Ciências, Saúde - Manguinhos, Rio de Janeiro, v.21, n.1, jan.-mar. 2014, p.15-35.

PERELMAN, Chaïm.; OLBRECHTS-TYTECA, Lucie. Tratado da Argumentação: a nova retórica. São Paulo: Martins Fontes, 1996.

PILATTI, A. A Constituinte de 1987-1988: progressistas, conservadores, ordem econômica e regras do jogo. 4. ed. Rio de Janeiro - RJ: Lumen Juris, 2020. v. 1. $334 p$.

POGREBINSCHI, Thamy. Judicialização ou Representação? Política, direito e democracia no Brasil. Rio de Janeiro: Elsevier, 2011.

RAMOS, D. T. O federalismo assimétrico. Rio de Janeiro: Forense, 2000.

SILVA, Jeferson Mariano. Mapeando o Supremo: As posições dos ministros do STF na jurisdição constitucional (2012-2017). Novos estud. CEBRAP, v.37, n.1, p.35-54, 2018.

VIANA, Ana Luiza d'Ávila; MACHADO, Cristiani Vieira. Descentralização e coordenação federativa: a experiência brasileira na saúde. Ciênc. saúde coletiva, vol.14, n.3, pp. 807-817, 2009.

VIANNA, Luiz Werneck. et al. A judicialização da política e das relações sociais no Brasil. Rio de Janeiro: Revan, 1999 
VIANNA, L. W.; BURGOS, M. B. Entre Princípios e Regras: Cinco Estudos de Caso de Ação Civil Pública. DADOS - Revista de Ciências Sociais, Rio de Janeiro, v. 48, n. 4, p. 777 a 843, 2005.

RIBEIRO, Leandro Molhano; ARGUELHES, Diego Werneck. Contextos da judicialização da política: novos elementos para um mapa teórico. Rev. direito GV, São Paulo, v. 15, n. 2, e1921, 2019.

STEPAN, Alfred. Para uma nova análise comparativa do federalismo e da democracia: federações que restringem ou ampliam o poder do Demos. Dados [online], vol.42, n.2, 1999.

TATE, C. N. Why the Expansion of Judicial Power? In: TATE, C. N.; VALLINDER, T. (Org) The Global Expansion of Judicial Power. New York, London: New York University Press, 1995.

TAYLOR, Matthew. O Judiciário e as políticas públicas no Brasil. Dados, Rio de Janeiro, v. 50, n. 2, p. 229 a 257, 2007.

TAYLOR, Matthew; DA-ROS, Luciano. Os partidos dentro e fora do poder: a judicialização como resultado contingente da estratégia política. Dados, Rio de Janeiro, v. 51, n. 4, p. 825-864, 2008. 